\title{
Bananas y otros frutos del deseo: divas y subversiones en la performance de Ney Matogrosso
}

\section{Bananas and other Fruits of Desire: Divas and Subversions in the Performance of Ney Matogrosso}

\author{
María del Pilar Jarpa Manzur \\ Universidad de Valparaíso \\ maria.jarpa@postgrado.uv.cl
}

\section{Resumen}

Teniendo en cuenta el universo simbólico de las dictaduras cívico-militares del Cono Sur como contexto, el presente artículo busca reflexionar en torno a los alcances estéticos y políticos de la figuración de la diva en la performance de artistas locales, a través del caso de Ney Matogrosso (1941) y su reapropiación de Carmen Miranda (1909-1955). Desde una orientación teórica feminista en clave poscolonial, es posible sospechar que la figuración de la diva es estratégicamente infiltrada en su performance, desde una red de superposiciones estéticas que apuntan a desestabilizar el orden simbólico dominante, volviendo porosas las fronteras entre lo masculino y lo femenino, lo político y lo espectacular. La relevancia de este estudio reside no solo en la tentativa de dar luz a este "gesto paródico de oropel" (Castillo 92) desde sus posibles efectos estéticos, sino también aportar al campo poco explorado de sus implicaciones (micro) políticas en el contexto latinoamericano.

Palabras clave: divas, travestismo, performance de género, dictadura.

\section{Abstract:}

Taking into account the symbolic universe of the civic-military dictatorships of the Southern Cone as a context, this article seeks to reflect on the aesthetic and political implications of the figuration of the diva in the performance of local artists, through the case of Ney Matogrosso (1941) and his reappropriations of Carmen Miranda (1909-1955). From a feminist theoretical orientation in a postcolonial key, it is possible to suspect that the figuration of the diva is strategically infiltrated in its performance, from a network of aesthetic superposition that aim to destabilize the dominant symbolic order, rendering porous the boundaries between masculine and feminine, the political and the spectacular. The relevance of this study lies not only in the attempt to shed light on this "parody tinsel gesture" (Castillo 92) from its possible aesthetic effects, but also to contribute to the unexplored field of its (micro) political implications in the Latin American context.

Keywords: divas, transvestism, gender performance, dictatorship. 


\section{Divas y travestismo: algunas consideraciones preliminares}

Subvirtiendo los proyectos oficiales de uso y consumo de la sociedad del espectáculo, la apropiación de la figuración de las divas en la performance travesti ${ }^{1}$ se registró en diversos contextos socio-culturales desde principios del siglo xx. Zarah Leander (1907-1981), Marlene Dietrich (1901-1992) y Greta Garbo (1905-1990) son algunos de los nombres que emplumaron esta puesta en escena, reservada en principio solo a circuitos clandestinos de socialización homoerótica. ${ }^{2}$ A partir de los años 60, estas prácticas comenzaron a materializarse en el espacio público, agenciando variadas superficies de registro: literatura, música, artes visuales, entre otras. Desde acciones individuales a manifestaciones colectivas, la iconografía de las divas fue también recurrente en contextos de violencia política extrema. Cabe mencionar no solo la mítica sublevación de Stonewall (1969), inspirada en la figura de Judy Garland (Halperin 60). En América Latina, diversos registros permiten sospechar que la estética divesca fue también parte de un arsenal político de múltiples prácticas de desacato, especialmente frente a las prescripciones homo y transfóbicas de las dictaduras cívico-militares de la segunda mitad del siglo xx. Dictaduras que no solo implementaron modelos económicos y políticos que extremaron las desigualdades sociales, sino también disciplinamientos encubiertos que se introdujeron en cada fisura del cuerpo social. Dentro de sus consecuencias, cabe subrayar la intensificación de un orden simbólico profundamente patriarcal, a partir del cual el binomio masculino/ femenino se consolidaría como parte de los extremos irreconciliables entre poder y subordinación y a veces también entre la vida y la muerte. ${ }^{3}$ Bajo el argumento de una mixtura entre agitación sexual y política, la represión no solo se proyectó hacia la autonomía de las mujeres, sino también hacia la prevención de la revuelta potencial que este femenino podría encarnar. Dilatando sus espectros, el orden del castigo se extendió sobre quienes osaban hacer guiños a este "femenino", transgrediendo los límites heteronormativos de sexo y género. No es un dato irrelevante el hecho de que muchos centros nocturnos de la bohemia ciudadana quedaran convertidos en lugares de detención. ${ }^{4}$ La noche - esfera antes privilegiada de la socialización homoeróticaquedaría desarticulada y consecutivamente expuesta a toques de queda, redadas y allanamientos (Olavarría 19).

1 Desde la crítica cultural latinoamericana, Richard define el travestismo como "una figura que conjuga paradójicamente la máscara y lo femenino en una zona de ambigüedades que lleva la marca siempre inquietante de la indefinición, del tumulto, de la incerteza sugerida por un 'tal vez"' (191). Considerando las múltiples clasificaciones actualmente en uso para definir tránsitos identitarios que desestabilizan los lineamientos heteronormativos - trans, drag, crossdressing, etc.- , he optado por esta definición local del travestismo, que ciertamente enriquece y a la vez desafía su aproximación, al imposibilitar su delimitación en categorías fijas y universales.

2 Para una revisión exhaustiva de este tema, ver Rosenberg.

3 Para más información sobre formas sistemáticas de violencia de género, ver Jelin.

$4 \mathrm{Al}$ amparo del discurso médico-jurídico en torno a "los anormales", la dictadura brasileña (1964-1985) consagró la homofobia como política de estado, a través de la "caza de travestis" para la "limpieza" ciudadana. Ver Green y Quinalha. 
Desde estas consideraciones de contexto surge la pregunta por las subversiones que podrían promoverse a partir de la reapropiación de las divas. Figuraciones que en principio resultan inquietantes por su sospechoso anclaje a los lineamientos colonialistas y neocolonialistas del mercado, en este caso reafirmados por un proyecto neoliberal de alto impacto en los países del Cono Sur. Parte de la crítica cultural metropolitana ${ }^{5}$ sostiene que, en el marco de las hegemonías de la primera mitad del siglo $\mathrm{xx}$, estas mujeres circularon por las fronteras ideológicas como fetiches de la mercancía, a lo que en lo sucesivo habría que agregar su rol detonante en las políticas de "buena vecindad", como punto de cruce de la industria cultural, la colonialidad del poder y parte de la historia de dominación sobre América Latina. ¿Qué relación cabría entonces entre esta aparente frivolidad mercantilizada y las resistencias frente a las violencias dictatoriales? ¿Cómo la figuración de la diva podría pasar de ser un recurso del poder a ser una estrategia micropolítica de poder? ${ }^{6}$

El objetivo del presente artículo es reflexionar en torno a los alcances estéticos y políticos de la figuración de la diva en la performance de artistas locales en contextos de dictadura, a través del caso del cantante brasileño Ney Matogrosso. La hipótesis que orienta mi investigación es que la figuración de la diva es estratégicamente infiltrada en su performance desde una red de superposiciones estéticas que apuntan a desestabilizar el orden simbólico dominante, volviendo porosas las fronteras entre lo masculino y lo femenino, lo político y lo espectacular. Desde mi perspectiva, la relevancia del estudio que presento reside no solo en dar luz a este "gesto paródico de oropel" (Castillo 92) desde sus posibles efectos estéticos, sino también aportar al campo poco explorado de sus implicaciones (micro) políticas en América Latina.

A fin de indagar estas prácticas contradiscursivas, he considerado como eje analítico central el concepto de performance de género, ${ }^{7}$ a partir de la teoría filosófica de Judith Butler. Desde este margen recursivo es posible entrever cómo las categorías de sexo y género se han inscrito culturalmente sobre los cuerpos, con base en un supuesto sustrato ontológico. En el marco de las relaciones de poder, estas inscripciones son naturalizadas a través de prácticas discursivas reiteradas y funcionales a la perpetuación de la dominación. Sin embargo, este campo de restricciones puede ser

5 Para más información sobre este tema, ver Morin, Benjamin, y Debord.

6 Braidotti establece una distinción entre el poder en su dimensión negativa y prohibitiva: potestas y el poder como potentia positiva que impulsa intensidades, deseos y resistencias: "El poder es negativo (potestas) en tanto que prohíbe y constriñe. También es positivo (potentia) en tanto que inyecta fuerza y capacita” (Metamorfosis 37).

7 Si bien el presente artículo releva principalmente la performance desde una perspectiva de género, el campo de estudio propuesto se constituye a partir de prácticas que acontecen en el marco de proyecciones artísticas. Siguiendo a Taylor (Estudios avanzados 7-30), es importante tener en cuenta la configuración conceptual polisémica de la noción de performance, la cual posibilita la trascendencia de fronteras disciplinarias en sus ensamblajes con lo social, lo político, lo artístico y lo ritual. Desde esta perspectiva, la noción de performance puede operar como la descripción de un acto - artístico o no- y a la vez como un lente "postdisciplinar" (Estudios avanzados), que hace posible explorar una amplia variedad de archivos y repertorios culturales (El archivo). En este sentido, tanto las prácticas encarnadas de Carmen Miranda como las de Ney Matogrosso parecen desbordar los límites de sus respectivos contextos escénicos, fisurando las fronteras categoriales entre arte y política, sexo y género. 
a la vez el territorio de una reversibilidad inesperada. Butler advierte que "así como las superficies corporales se representan como lo natural, estas superficies pueden convertirse en el sitio de una actuación disonante y desnaturalizada que descubre el carácter performativo de lo natural en sí" (El género 284). Disonancia que se materializa a través de la parodia, en cuanto práctica subversiva que lleva explícitamente a la desconstrucción de la noción de un original. Desde la perspectiva de Butler, la "risa subversiva" de las prácticas paródicas reside precisamente en evidenciar que "lo original, lo auténtico y lo real también están constituidos como efectos” (284). Es este un punto especialmente relevante dentro del abordaje teórico propuesto. Desde la expropiación del discurso dominante, el uso paródico de la figuración de las divas abre múltiples lugares de resignificación subversiva al romper con el contexto originario en que se "debía" haber "generado". Sin embargo, considerando los casos propuestos en el presente estudio, habría que atender no solo a las prácticas subversivas de Ney Matogrosso sino también a la "actuación disonante" de las propias divas. ¿En qué sentido estas mujeres actúan a su vez el género? ¿Pueden desmarcarse de alguna manera del propio sistema que las consagra? ¿Es posible que Carmen Miranda haya contribuido "en sus efectos" a horadar este sistema desde dentro?

La línea teórica precedente será abordada a la luz del barroco latinoamericano, en cuanto perspectiva poscolonial que posibilita cruces hermenéuticos para el análisis contextual de las prácticas artísticas propuestas. Más allá de representar un modelo epocal que se reproduciría miméticamente en ultramar a partir de transcripciones subalternas, Mabel Moraña (113) sugiere que en América Latina el barroco funciona como paradigma, significante cultural irresuelto, dinámico y bifronte a la vez. Es precisamente esta doble faz la que posibilita "la duración, la fuerza y energía productiva del principio barroco, y su consecuente proyección a lo largo de todo el desarrollo histórico de la cultura americana" (7). Si, por una parte, parece reiterar las marcas sociales y culturales homogeneizantes del discurso dominante, al mismo tiempo apropia, altera y manipula un vasto repertorio de recursos. Apropiación y a la vez recuperación que se expresa en una producción (contra) cultural irreductible y original, hecha de máscaras, carnaval, claroscuros y pliegues (147), que contribuyen a descentrar y relativizar las cosmovisiones metropolitanas del poder.

Considerando estos ejes teóricos, el diseño metodológico de la investigación se centra principalmente en la pose como recurso analítico que permite identificar las formas en que se construye y deconstruye un campo de visibilidad performativa. $\mathrm{Si}$ bien la pose ha sido teorizada por diversos autores (Barthes, Owens, entre otros) me interesa especialmente la propuesta epistemológica de Sylvia Molloy, por ofrecer una reflexión novedosa en torno al cruce entre género, sexualidad, política y arte en América Latina. Según Molloy (Poses 49) la epistemología de la pose remite a un doble itinerario: a una postura significante que una vez visible deviene una impostura significante, no necesariamente reversible. Entre ser y parecer, la pose se despliega como práctica de provocación a través de la exhibición, el artificio y la exageración de diversos signos 
que perturban las economías del deseo. En este sentido, señala Molloy: "exhibir no solo es mostrar, es mostrar de tal manera que aquello que se muestra se vuelva más visible, se reconozca" ("La política” 130). En cuanto herramienta analítica, la pose proporciona claves procedimentales para el abordaje cualitativo de diversas superficies de registro - fotográficas, documentales, escriturales, ficcionales- haciendo posible su articulación dialógica.

El corpus de la investigación se compone de archivos que registran repertorios performativos de la obra de Ney Matogrosso - videoclips, carátulas de discos, fotografías, entrevistas - producidos entre 1978 y 1979. Corte temporal que se debe a su reapropiación de la diva en el contexto dictatorial brasileño. De esta producción se dará especial atención al show Feitiço, realizado en Río de Janeiro en el año 1978 y dedicado en parte a Carmen Miranda. De la diva brasileña se revisarán principalmente los archivos fílmicos de Banana da Terra (Costa), The Gang's All Here (Berkeley), así como documentos visuales - fotografías, entrevistas, documentales - que contienen detalles ornamentales citados en la performance de Matogrosso.

En la primera parte del artículo abordaré algunas de las principales perspectivas críticas en torno a la figura de Carmen Miranda y su polémico rol en la reproducción de estereotipos de raza, clase, sexo y género, con especial énfasis en la iconografía de la banana. La segunda parte se centrará en los usos performativos de la figuración de la diva en la obra de Ney Matogrosso. A partir de sus múltiples subversiones respecto al orden simbólico patriarcal de la dictadura cívico-militar brasileña, se indagarán las complicidades paródicas que podrían estar operando en las superposiciones estéticas y políticas de su performance. Por último, a modo de conclusión, se delinearán posibles lugares comunes que permitan comprender en qué sentido - pese a la distancia en el tiempo y los espacios culturales- estos/as artistas se movilizaron como referentes de antiguas y futuras irreverencias.

\section{"Bananas is my business": bananización y parodia en la performance de Carmen Miranda}

Desde la epistemología de la pose - homoerótica, amanerada, feminizante-, Molloy (Poses) insiste en la importancia de observar los detalles que residen en la materialidad del retrato y el relato, incluso a partir de elementos a primera vista (in)significantes. El estudio de estos fragmentos discursivos no solo puede desembocar en "una iluminación que alumbra toda la obra" (Pavis 178), sino también alumbrar sugestivamente las fisuras entre ser y (a)parecer, a fin de develar gestos políticos emergentes en contextos cuya "fuerza desestabilizadora" amenaza los pactos culturales de sexo y género (Molloy, "La política" 129).

Desde esta perspectiva, y dentro del exuberante despliegue de objetos que ornamentan la performance de Matogrosso, la banana se erige como una pieza fundamental 
de sus primeras incursiones como solista en el campo de la música popular brasileña (MPB). Si en principio este fruto podría parecer un brillo más en medio de su ajuar travesti, una aproximación más detallada permite entrever sugerentes improntas en sus prácticas de subversión, incardinadas a su reapropiación performativa de la controvertida diva Carmen Miranda. Si bien un examen exhaustivo de la banana excedería los límites del presente artículo, considero importante abrir al menos algunas de sus potenciales resonancias en el contexto extensional de la performance. Sobre todo, considerando que este fruto del deseo no deja de remitir a una larga historia de dominación sobre América Latina.

Desde una perspectiva poscolonial es posible inferir que, así como la orientalización de oriente (Said) se reforzó durante siglos a través de un exotismo visualmente materializado en imágenes de odaliscas, danzarinas y encantadores de serpientes, la banana se fue trocando en el icono que - desde el siglo XIX - consolidaría la "bananización" de América Latina (Galeano 91). Parafraseando a Moraña (54), se podría afirmar incluso que, en este contexto, el problema de la construcción del "otro" no fue solo representacional sino también, y sobre todo, epistemológico, a fin de reducir, regular y homogeneizar la otredad cultural a la episteme del dominador y - de paso- legitimar ideológicamente la explotación.

En los bordes detonantes del siglo xx, el monopolio norteamericano sobre la fruta se estableció estratégicamente a través de multinacionales como la United Fruit Company, a fin de someter — como señalara Adams - a aquellos "afortunados nativos de los trópicos que no tienen nada que hacer, sino deambular por los claros floridos y vivir en los bananos" (21) [traducido por la autora]. En lo sucesivo, esta hegemonía no solo se reafirmaría desde los discursos políticos y económicos sobre las "repúblicas bananeras", sino también a través de diversos dispositivos de poder mediático, infiltrándose en cada una de las esferas de la producción cinematográfica. Los inquietantes guiños de algunos gobiernos latinoamericanos hacia el nazismo alemán desencadenaron una intensificación de las estrategias mediáticas. En 1933 el gobierno de Roosevelt puso en práctica la política externa de buena vecindad, de la cual se derivaría en 1940 una división especial de relaciones culturales con el nombre de Office of The Coordinator of Inter-American Affairs (CIAA). Bajo los tópicos recurrentes de lo erótico y lo exótico, este organismo actualizó el arsenal de estereotipos sobre América Latina, reiterando subrepticiamente la asimetría de las relaciones de poder y su inmenso aparataje de violencias. Refiriéndose a esta división, Balieiro señala:

Entre sus diversos frentes, uno de ellos estimulaba e intervenía en filmes alineados con la "política de buena vecindad". En este momento, el cine producido en Hollywood pasó a trabajar cada vez más con contextos y personajes latinoamericanos (55) [traducido por la autora].

Es en este contexto de re-bananización, con fuerte arraigo en la industria cultural, en el cual Carmen Miranda irrumpe en la escena del espectáculo. La mayoría de los 


\section{FIGURA 1}

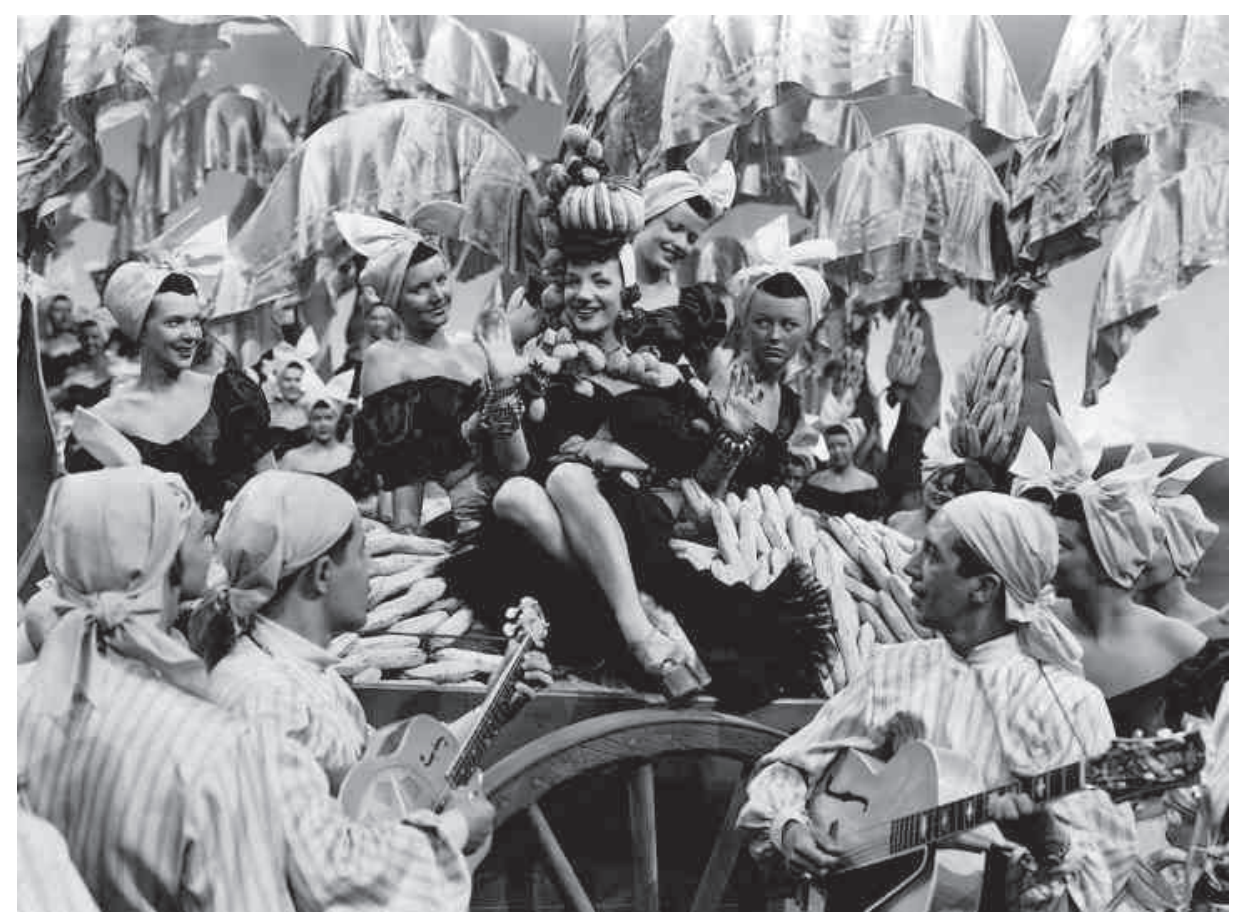

Carmen Miranda, en The Gang's All Here (Berkeley). Fuente: https://commons.wikimedia.org

estudios revisados para la presente investigación coinciden en considerar a la diva como una figura no solo central, sino además complicitaria en la reproducción masiva de la iconografía de la banana. De Río a Broadway, su carrera habría sido el mejor ejemplo de promoción de las políticas de "buena vecindad", sirviendo a los objetivos imperialistas para presentar un "otro" amistoso, sensual, primitivo y feminizadamente explotable. ${ }^{8}$ Así, espejeando la colonialidad del poder, la estrella y sus bananas serían reducidas a la manipulación consentida de una voz cargada de sambas con "olor a rumba" y una cabeza que no servía más que para sostener un interminable turbante de bananas.

Se puede argumentar que Miranda, como la cara de América Latina en Hollywood, fue cómplice en la creación de una identidad colectiva para los latinoamericanos que los desvalorizó como lo Otro exótico, erótico y primitivo, la cual borró su identidad cultural y fue utilizada por los Estados Unidos para justificar la violencia del imperialismo (Baker 12).

Con todo, el arte suele fisurar incluso las hegemonías más cristalizadas. En El género en disputa, Butler señala que, pese a la normatividad del discurso, "Los géneros

8 En esta línea pueden inscribirse los estudios de Jenkins; Baker. 


\section{FIGURA 2}

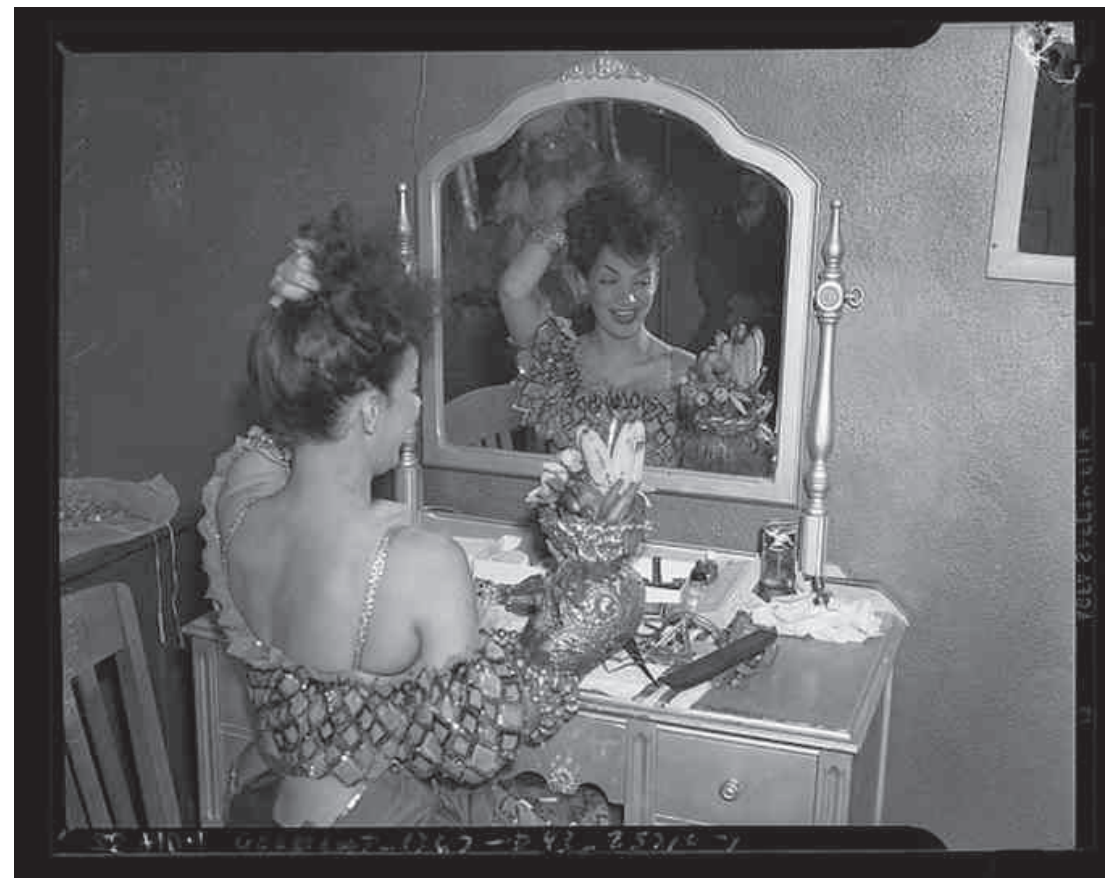

La actriz Carmen Miranda en el tocador con su sombrero de frutas, en Los Angeles Daily News (1941). Fuente: https://commons.wikimedia.org

también pueden volverse total y radicalmente increíbles" (275). Idea que introduce a partir del prodigioso travestismo de la diva sueca Greta Garbo, sugiriendo que independientemente del "sexo verdadero" que se escondiera detrás, finalmente todo -incluso el sexo- es encarnación:

Garbo se engalanaba como una "travestida" siempre que tenía que representar a un personaje muy glamoroso, siempre que se fundía dentro o fuera de los brazos de un hombre, siempre que sencillamente dejaba que ese cuello divinamente inclinado [...] sostuviera el peso de su cabeza echada hacia atrás [...] ¡Qué resplandeciente parece el arte de actuar! Todo es encarnación, sea o no verdadero el sexo que se esconde detrás (253).

Aunque Butler anuncia la idea de una cadena de resignificaciones sin un origen, su análisis se detiene en los "actos corporales subversivos" de la parodia travesti. No obstante, existe una lumínica complicidad en estas encarnaciones que parece no agotarse en este punto de la cadena. Volviendo a la noción de performance es importante subrayar que, desde la perspectiva de Butler, la acción del género requiere de una actuación repetida y ritualizada para su legitimación cultural, consistente en "volver a efectuar y a experimentar una serie de significados ya determinados socialmente" 
(El género 273). Pero si bien quienes actúan operan "desde el principio" dentro de un campo de restricciones, estas "son al mismo tiempo posibilidades" de resignificación y subversión (Butler, Lenguaje 37):

Si el cimiento de la identidad de género es la repetición estilizada de actos en el tiempo, y no una identidad aparentemente de una sola pieza, entonces, en la relación arbitraria entre esos actos, en las diferentes maneras posibles de repetición, en la ruptura o la repetición subversiva de este estilo, se hallarán posibilidades de transformar el género (Butler, "Actos" 297).

Es en estos actos de "ruptura" o "repetición subversiva", donde el cuerpo juega un rol fundamental, en cuanto potencial sitio de captura, pero también de insospechadas revueltas.

Desde los Star Studies, Dyer deja entrever que una estrella no solo se consagra a través de la producción. Entre esta y la recepción hay una dimensión intertextual, desde la cual es posible introducirse en la imprevisibilidad de reapropiaciones que desbordan los límites originalmente concebidos a una estrella (Benavente). Son precisamente los estudios intertextuales en torno a la diva - especialmente desde su recepción camp- los que proponen otros sentidos posibles a su complejidad estelar. ${ }^{9}$ Desde estas lecturas se visibiliza una Carmen Miranda que lejos de someterse a los disciplinamientos del Star System supo negociar y hasta burlar sus proyecciones patriarcalizadas y etnocéntricas. Aún envuelta entre bananas y café, su performance contribuyó a horadar desde dentro los estereotipos esencialistas que debía reafirmar, impugnándolos a través de la risa, la parodia y la exageración de su insurgente carnaval.

Siguiendo el principio del barroco latinoamericano, formulado por Moraña (7), sería posible poner en perspectiva estas prácticas performativas desde sus reiteradas irreverencias de raza, etnia, clase, pero también de sexo y género.

En este sentido, no es un antecedente menor su relativa autoría en el diseño de ornamentos, danzas e interpretaciones vocales (Balieiro 302). La complicitaria relación entre su performance y la cultura afro-diaspórica, por ejemplo, derivó en una composición carnavalesca que introduciría creativas superposiciones estéticas entre "el samba, lo burlesco y las revistas musicales" (Coelho 62). Su cantar falado - rítmica y onomatopéyicamente hablado, recitado y en muchos casos "trabalenguado" (Shaw 79) - incorporó variadas influencias de las cantoras de los teatros de revista, pero también de las tradiciones orales locales, impactando así el devenir de la música popular brasileña, mucho más allá de sus difusiones mediáticas.

Por otra parte, su reapropiación performativa de la figuración de las bahianas del nordeste de Brasil contribuyó a reinterpretar y visibilizar cruces devocionales, musicales e incluso culinarios, con marcados guiños a las esferas rituales del candomblé (Amaral 202). En este entramado de saberes y sabores, la lengua pregonera de la diva

9 Para más información sobre este tema, ver Balieiro; Roberts. 
no dejó de cantar al vatapá, al acarajé y al camarão ensopadinho com chuchu, aun cuando nadie en el Broadway de los años 1940 entendiera sus apasionadas saudades. ${ }^{10}$ Turbantes, sandalias, vuelos y balangandãs fueron también parte de esta re-creación de las bahianas. A través de su exuberante combinación de texturas y colores, la diva fue instalando lumínicas fisuras que, desde el estilo, alterarían los lineamientos etnocéntricos de la moda. Refiriéndose al impacto de sus atuendos en Estados Unidos, Balieiro señala que: "entre lo exótico y lo brillante, Carmen construye una visión que se aleja de una feminidad pasiva” (119).

Pero tal vez uno de los ejemplos más sugestivos y a la vez arriesgados de sus mixturas performativas esté en los desacatos de la diva frente a las exigencias segregacionistas de la industria norteamericana y sus blindados estados. Ruy Castro, uno de los principales biógrafos de Carmen Miranda, anota con especial énfasis el episodio que la diva protagonizó en el Roxy de Nueva York, en 1942, junto a los Nicholas Brothers. En el centro de la escena, Miranda no solo se "atrevió" a danzar entrelazada a músicos "negros", sino además a contestar las imprecaciones racistas de su público, con un desafiante: “¿Cuál es el problema?”, “Está con celos, ¿Yes?” (343).

En la década del 40, no era normal que una artista blanca (incluso "latina") tocase o fuese tocada físicamente por un negro en un escenario de Nueva York. Y menos aún por dos negros. O, peor aún, que además de tocar y ser tocada, se enroscara con ellos al bailar (343).

En lo tocante a las bananas, varios episodios de la carrera de la diva dan cuenta de su "risa subversiva". En su rol de entertainer, por ejemplo, solía sacar su turbante de frutas en medio del show para mostrar que debajo tenía cabellos tan rubios como las otras divas hollywoodenses, revelando en seguida su falsedad tinturada. ${ }^{11}$ Otras veces descendía del escenario repartiendo bananas, declamando entre risas que ya no le importaba perder su empleo si, después de todo, podría comer de su turbante. En fin, haciendo de las bananas un sello de su propia parodia, evidenció incluso las discriminaciones al interior de los estudios cinematográficos, al emplazar irónicamente a su productor por no permitirle rodar una escena con Clark Gable, solo porque ella hacía su dinero con bananas. ${ }^{12}$

En su sugestivo estudio sobre la diva, Balieiro aborda su relación complicitaria con el público homosexual masculino de la época, la cual - sugiere el autor- no puede ser reducida a un incidente meramente anecdótico en su carrera (252-274). A partir de datos biográficos - testimoniales y documentales- es posible entrever no

10 La íntima relación de Carmen Miranda con los sabores del candomblé fue especialmente explícita —según refiere Amaral - en sus reivindicaciones sonoras de "la comida vendida por las bahianas, que incluía los mismos bocados exquisitos ofrecidos a los/as orixás y conocidos como 'comida de santo"' (202).

11 Un ejemplo de estas prácticas paródicas puede apreciarse en una entrevista realizada en Londres (1948). Web 21 jul. 2018 https://www.youtube.com/watch?reload=9\&v=z4zj1fez3G0

12 El registro completo de esta declaración está disponible en Web 21 jul. 2018 https://www.youtube.com/ watch? $v=J W f t X H j J 2 w I$ 
solo las múltiples reapropiaciones de Carmen Miranda en diversos contextos de la homoerótica urbana, sino también su propia participación en este proceso. Además de frecuentar clubes nocturnos en los que se realizaban performances drag, la actuación hiperbólica de la diva parece haber promovido implícitamente señales disidentes, a través de sus atuendos y gestualidades, pero también desde la ambigüedad de las letras de sus canciones. Es el caso, por ejemplo, del uso del término gay en la canción The Lady in the Tutti-Frutti Hat, tal vez la más emblemática de la película The Gang's All Here.

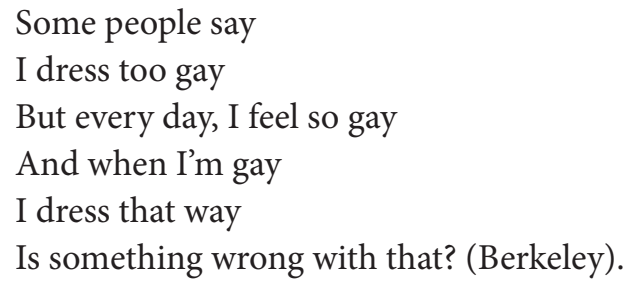

Aun cuando en inglés el término gay podría ser atribuible a una alegría más bien indiferenciada, no deja de denotar un doble sentido, recibido y resignificado en las lecturas disidentes de su época (Balieiro 252). En tiempos venideros, estos y otros matices estéticos de la producción artística de Carmen Miranda movilizarían deseos otros, tornando a la diva un icono de diversas transgresiones, además de propiciar el despliegue de una performatividad posible en el devenir de otros cuerpos desafiantes.

\section{Yes, nós temos bananas: reminiscencias de la diva en la performance de Ney Matogrosso}

Cuando Ney Matogrosso, la loca más fulgurante del gay carioca inauguró el primer Rock in Río, pareció establecerse un precedente [...] Pero al correr el espectáculo, las alas de murciélago en las orejas de Ney parecían no escuchar las pifias y gritos de desagrado de los heavy-metal, asqueados por la operática flauta de la bicha. Más de cabaret travesti que de rock concert. Más de Dama de las Camelias que de Jimmy Hendrix (Lemebel 97-98).

Como punto de partida, es importante señalar que Ney Matogrosso entra en la escena del espectáculo circulando inicialmente entre el mainstream y el underground, en el momento en que la dictadura cívico-militar brasileña pasaba por una de sus "fases más violentas" (Zan 282). Sus primeras incursiones fueron en 1973 como vocalista de la banda de glam rock Secos y Molhados, en la que — relata Matogrosso- literalmente le fue concedido un metro cuadrado. 
Pregunté a los responsables del proyecto cuál era mi espacio y ellos respondieron que había aquel metro cuadrado. Les pregunté nuevamente si podría hacer lo que quisiese en aquel metro cuadrado. La respuesta fue... “iTodo!”. Entonces comencé a enloquecer (cit. en Queiroz 44).

Este espacio, en principio reducido, se fue trocando en una imprevisible línea de fuga, desde donde Matogrosso comenzaría a tensionar los límites de la industria cultural, reivindicando a través de su performance cada una de las imposibilidades lógicas de un orden binario profundamente falogocéntrico y por ende "antinómade" (Braidotti, Sujetos 73). En cuanto "lógica interna del patriarcado" (174), el falogocentrismo está en el centro de la crítica ofrecida desde la perspectiva posmoderna de los devenires minoritarios, donde toda ruptura con los modos universalistas de dominación "comienza y pasa por un devenir-mujer" (Guattari y Rolnik 100). Deriva deseante que se relaciona con una "economía del deseo" que potencia la desestabilización de las formas dominantes centradas en la subjetividad masculina y en la división binaria de los sexos; históricamente marcadas por la prohibición de este devenir. Pero ¿cómo puede acontecer un devenir mujer que realmente permita descentrar al sujeto masculino de su posición extrema de poder?

Distante de toda fantasmagoría fálica — psicoanalítica o filosófica-, el devenir mujer no funciona por imitación, identificación, correspondencia o apariencia de algo, sino que es "perfectamente real" (Deleuze y Guattari 244). Realidad que no apunta a la fijeza de los significantes discursivos en los que se deviene - en este caso "la mujer" - , sino al propio proceso del devenir. En palabras de Braidotti, el devenir mujer es "el detonante de la deconstrucción de la identidad fálica a través de una serie de pasos deconstructivos que retrasan, en sentido inverso y con la finalidad de desintegrarlas, las diferentes etapas de la construcción histórica de esta y de otras diferencias" (Metamorfosis 104). De este modo, este proceso del deseo hace posible el despliegue de una multiplicidad de diferencias "positivas" y subjetividades nómades que desafían la seguridad ontológica de los universales.

Desde las consideraciones anteriores es posible volver a los "actos corporales subversivos" de Ney Matogrosso, en sus múltiples nomadías identitarias. En 1978 - ya como solista- lanzó su disco Feitiço, el que fue censurado y retirado del mercado por atentar contra los lineamientos morales de la dictadura cívico-militar brasileña. La contraportada del disco introducía su sensual desnudo, enrevesado entre velos y rosas blancas, en señal de "ofrenda a los Orixas" (Da Silva 319).

En un estudio reciente sobre las carátulas de discos del MPB en el período dictatorial, Rodrigues (2-14) reflexiona sobre la forma en que los diseños gráficos tradujeron visualmente el posicionamiento disidente de diversos/as artistas. En el caso de Matogrosso, las carátulas no fueron un mero rótulo para anunciar gráficamente el producto o proteger el embalaje de una producción mayor, sino que funcionaron en sí mismas como escenificaciones performativas de un deseo otro, irreverente ante 


\section{FIGURA 3}

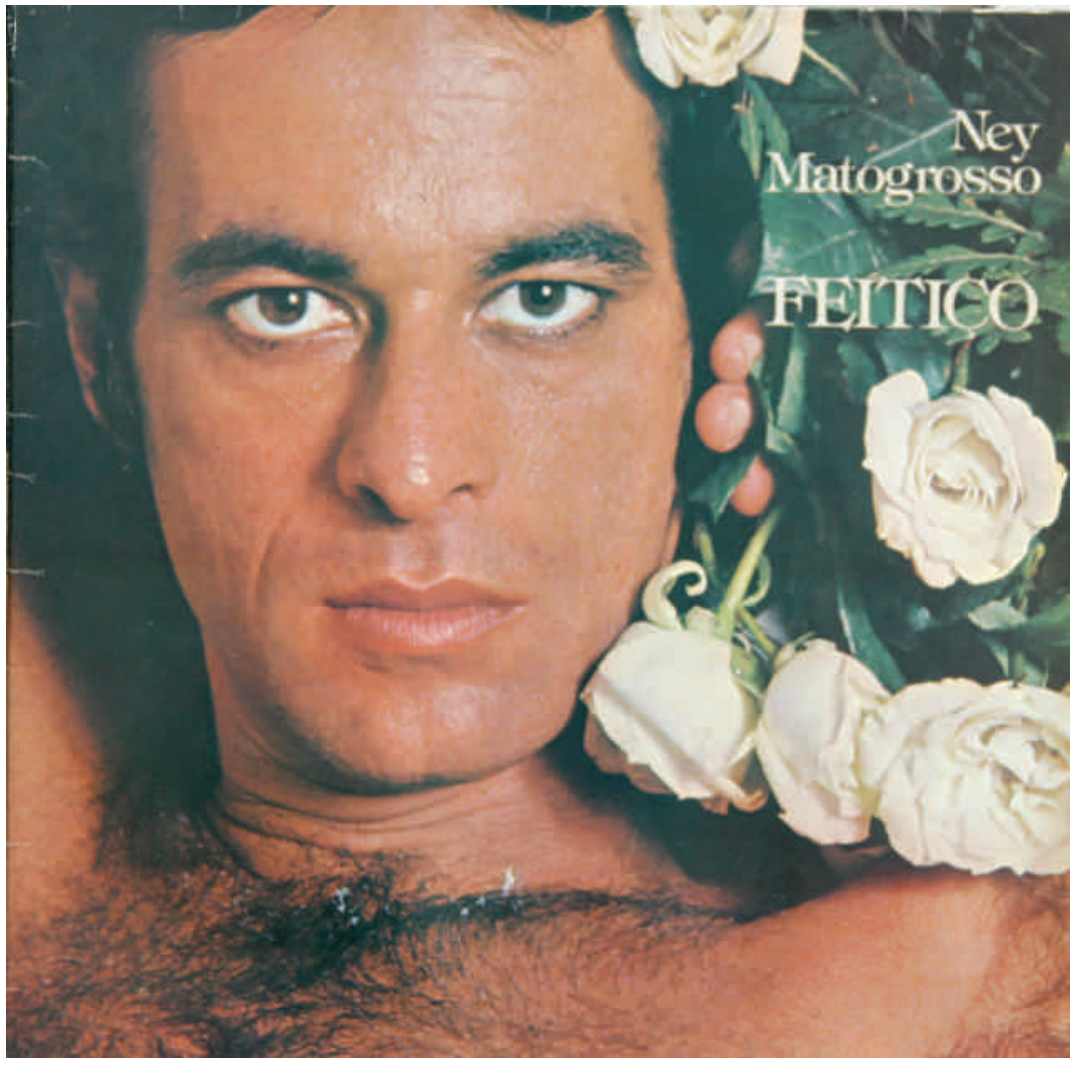

Carátula del LP Feitiço, en Matogrosso (1978).

\section{FIGURA 4}

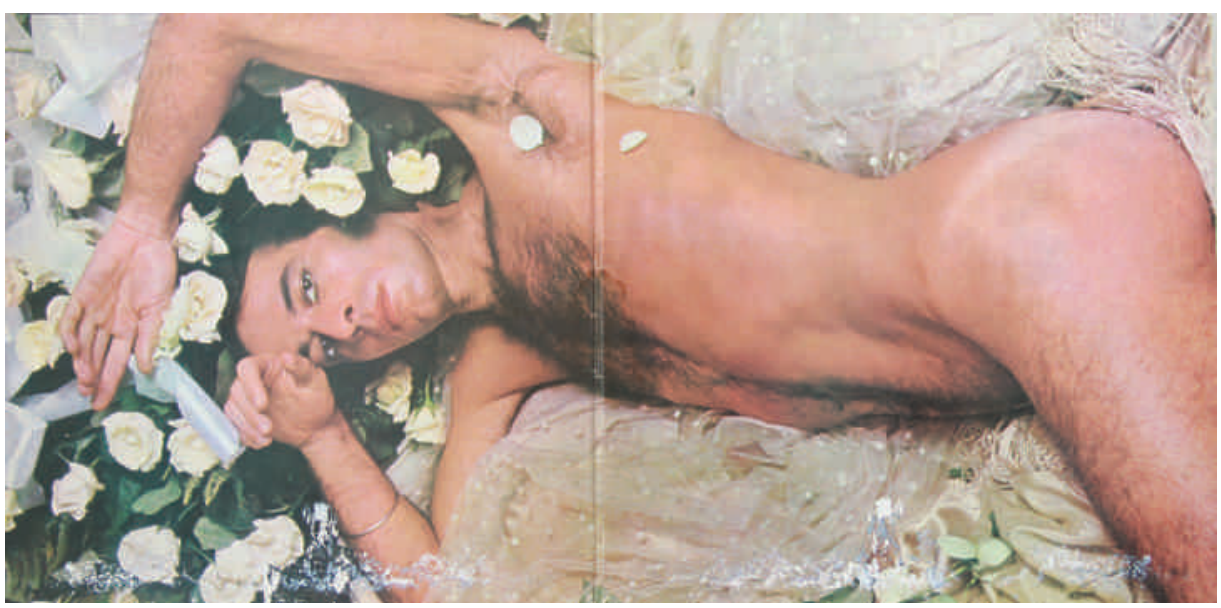

Interior del LP Feitiço, en Matogrosso (1978). 
los códigos heteronormativos dominantes. Un reportaje de la época describe parte de su impacto mediático:

Pensando bien, ¿qué más le resta a Ney Matogrosso? La carátula doble del último LP, abierta de par en par en la vitrina de una popular tienda carioca, dio la respuesta: desnudo entre velos y rosas blancas, Ney ofrecido en su belleza felina, angulosa y sensual a la curiosidad pública. ¡Y cómo! "Órdenes superiores" exigieron que esta "ofensa a la moral y a las buenas costumbres" fuese removida de la vitrina (Bahiana).

La propuesta visual del LP Feitiço tuvo su continuidad ritual en la gira que promocionó el disco, culminando con la inauguración del Teatro Alaska en Río de Janeiro. Espacio hasta entonces calificado como un antro del cine porno, "lugar de citas de travestis, homosexuales y 'garotos de programa"' (Queiroz 14). Burlando la censura, esta vez el cantante se presentó no solo vestido sino glamorosamente travestido. Su escenografía evocaba los tiempos áureos de los teatros de revista de la década del cuarenta. Bananeras, estrellas y canastas de mimbre aparecían como telón de fondo de mil quinientas bananas cubiertas en purpurina. En el centro de la escena, Matogrosso hacía su entrada ataviado con una saya amarilla de interminables vuelos que caían en un insinuante rebaje al borde del pubis. Su torso desnudo solo estaba cubierto con largos collares de monedas en la parte del cuello y los hombros, que se replicaban en balangandãs y en el turbante rojo que cubría su cabeza. El espectáculo se abría al ritmo del clásico de Carmen Miranda, O tic-tac do meu coração.

Nueve y veinte. El show comenzó. El foco de luz muestra al ídolo por entero. Ahí está él, en lo alto de un taburete de madera: un gitano lleno de monedas en la cabeza, en el cuello, la calza de satín a lo Carmen Miranda, cubierta de vuelos y más vuelos. Torso desnudo, bien maquillado, por sobre todo malicioso. No tuvo que cantar para ser recibido con un "sabroso" que vino del medio de la platea (Borges).

Cito esta performance porque es tal vez la que mejor ilustra la reapropiación performativa de la diva, en una de sus versiones más desestabilizadoras. Diversos elementos escénicos pueden relacionarse a la estética carnavalesca de Carmen Miranda: la saya de vuelos amarillos recuerda el coro de señoritas en The Gang's All Here (Berkeley); las cestas de mimbre a los entretejidos de sus turbantes y las monedas podrían tal vez remitir al "mónei", deliberadamente mal pronunciado por la diva. Sin embargo, es la banana la que ilumina la escena, deslumbrando a través de la música, las texturas, el vestuario. Podría decirse - siguiendo a Pavis - , que este fruto deja de ser un accesorio para situarse en el "corazón de la representación" (190). Pero, más allá del orden de las representaciones, la performance de Matogrosso pareciera situarse precisamente en la fisura entre ser y (a) parecer. De lo especular a lo espectacular, el desafío de su pose no consiste en recrear sino sobre todo en crear. Y este parece ser el punto clave 


\section{FIGURA 5}

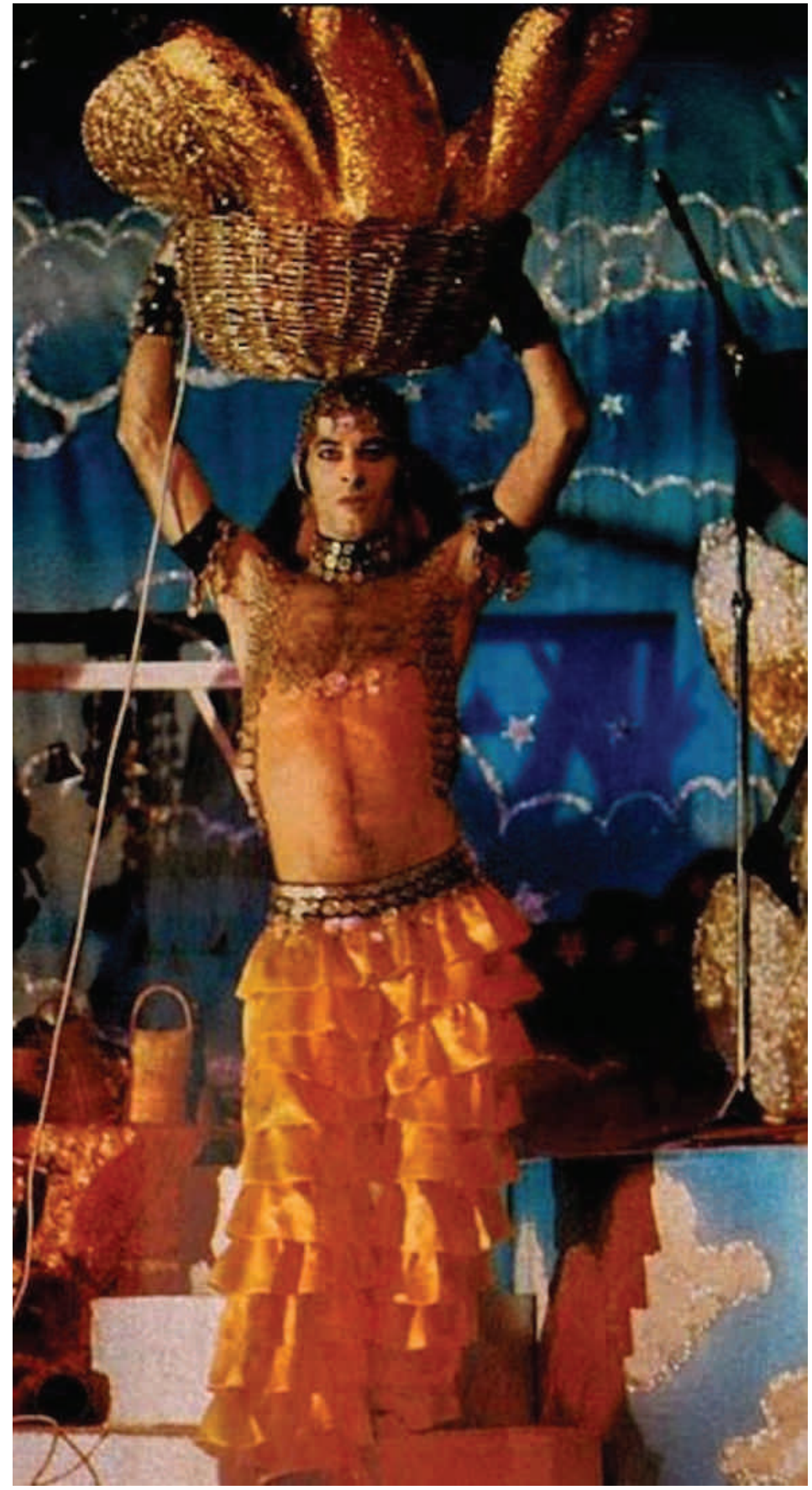

Ney Matogrosso en el Show Feitiço (1978), en Ney Matogrosso-Bau de raridades (26 jun. 2008). Fuente: http://neymatogrossobauderaridades.blogspot.com 
y provocador de su propuesta estética y política. A la voz que canta las saudades de la diva concurren enfocadas todas las fuerzas corporeizadas del sujeto, todos los hilos texturados del deseo. Sayas, brazaletes, canastas y monedas contribuyen a reforzar su voluntad de desacato. Pero es la banana, encarnada como una suerte de tercera piel, la que - en este caso- abre protuberancias que recogen y a la vez contestan los deseos (neo)colonialistas, desde múltiples e inclasificables cruces de sexo y género.

Especificando los alcances bifrontes de la performance de género, Butler ( $E l$ género 244) señala que la repetición paródica de los términos hegemónicos no solo puede develar la arbitrariedad de las relaciones entre significante y significado, sino además desestabilizar y movilizar los signos. En este sentido, la parodia revela y desplaza la naturalización que subyace a la construcción hegemónica de las identidades, volviendo inoperante la pretensión simbólica de un origen y la supuesta efectividad universal de su (re)producción. "En efecto y en sus efectos" (269), estas prácticas abren la posibilidad de infinitas recontextualizaciones, donde "la multiplicación paródica impide a la cultura hegemónica y a su crítica confirmar la existencia de identidades de género esencialistas o naturalizadas" (269).

Desde esta perspectiva, si la parodia del género no implica que exista un original imitado por las identidades paródicas, siendo "la noción misma de un original" lo que finalmente se parodia, la risa subversiva parece desbordar las prácticas travestis y ampliarse a lo que la propia Butler ha conceptualizado como una "cadena ritual de resignificaciones" (Lenguaje 35). Al seguir retrospectivamente el hilo subversivo de esta cadena, parece resolverse lo que había quedado en suspenso en su cita al prodigioso travestismo de Greta Garbo. Podría decirse incluso que tanto en las resignificaciones ritualizadas de Matogrosso como en el devenir indisciplinado de la diva, la producción de efectos sobre la piel se vuelve "increíblemente" desafiante por construirse en la superficie de las esencias, las verdades biológicas y el "sexo verdadero". Sus estilizados artificios generan un "juego de espejos” (Balieiro 244), parodia de una parodia, a través de la cual es posible comprender puntualmente cómo "lo original, lo auténtico y lo real" pueden llegar a constituirse como efectos (Butler, El género 284).

Con todo, "la expropiabilidad del discurso dominante" (Butler, Lenguaje 253) puede abrir múltiples lugares de resignificación subversiva, precisamente al desestabilizar el contexto de su "generación". Desestabilización que podría ser extensible a las materialidades y su carga discursiva, en este caso ancladas a la iconografía de la banana. Si el discurso dominante puede "ser devuelto de una forma diferente" y "citarse contra sus propósitos originales" (35), la declamación queer de los textos cantados por Matogrosso parece dar la "vuelta de tuerca" al término despectivo de república bananera, provocando una inversión subversiva de sus efectos. De la sonrisa a la carcajada, sus movimientos se despliegan reapropiando el gesto carnavalizante de la risa, explorada en otro tiempo por la diva. Si la risa remite al exceso - como propone Bajtin—, también se relaciona con la desacralización de los poderes estable- 
cidos. En el devenir de Matogrosso, esta risa es barrocamente apropiada para poner en escena no solo la inversión de los valores sino además su destronamiento. Desde un giro orgiástico, donde literalmente parece que todo "perdiese el pie" (Bataille 120), la banana - en cuanto metonimia del pene- se vuelve un instrumento del placer y no ya del poder. En medio de los atuendos que conjuran a la diva, el fruto parece funcionar como un fetiche texturado, en cuanto "punto de fuga del deseo". El sugerente nombre de feitiço - tanto para el LP como para el show que promociona su puesta en escena- anuncia las posibles resonancias de su "encanto o sortilegio" (Echavarren, Arte andrógino 25).

Más allá de la noción de fetichismo de la mercancía formulada por Marx y de la fantasmagoría fálica de sus connotaciones freudianas, las epistemologías del sur (Cangi; Echavarren, entre otros/as) proporcionan claves hermenéuticas en torno a los alcances estéticos, eróticos y políticos del fetiche. En este sentido, Echavarren (Arte andrógino 31) indica que su poder no reside en velar o (di)simular un supuesto soporte biológico, sino en abrir "superficies de registro", investidas por un deseo que excede incluso lo orgánico:

El fetiche no sustituye meramente el falo o la vulva, sino despliega una membrana, el tejido fascinante, el brillo de algo que nos interroga sin que sepamos por qué. Que nos atrae por su misterio. Tiene consistencia propia. Es una superficie de registro, un proyecto que no termina en un órgano, sino que abre la extensión de una textura, de una membrana o superficie que se podría cortar con un cuchillo (Echavarren, "Reseña" 4).

Exuberantes en sus brillos, resplandores y membranas, estas superficies se pliegan y despliegan en un movimiento lúdico entre miradas y objetos que se des-cubren. Desde la lectura de Echavarren es posible entrever que un objeto fetichizado - en este caso la banana - no es solamente contemplable, sino además reapropiable: "el fetiche, al menos en principio, puede ser vestido o encarnado por otros individuos, y además puede ser sustraído, separado de ellos" (Arte andrógino 35). A lo que sería importante añadir - siguiendo a Cangi (61-96) - que el fetiche proporciona un goce que acaba cuestionando, contaminando y finalmente borrando las diferencias entre lo masculino y lo femenino. En la performance de Matogrosso, las protuberancias texturadas de la banana desorganizan lúdicamente las superficies orgánicas del cuerpo, introduciendo recitaciones eróticas que impugnan un "código sexual trascendental falso" (Preciado 23), históricamente consagrado en la producción y reproducción de los poderes fálicos.

Así, las improntas discursivamente lacerantes del falo son redireccionadas hacia otros territorios de desplazamiento y emplazamiento del deseo que, a través del goce, liberan al "objeto" de sus agresiones políticas, económicas y sexuales. Esta irreverencia deseante es re-creada ejemplarmente por Matogrosso en la actualización performativa de la composición de Ribeiro (1937), que en otro contexto sirviera para burlar la hegemonía de la industria norteamericana sobre la fruta. 


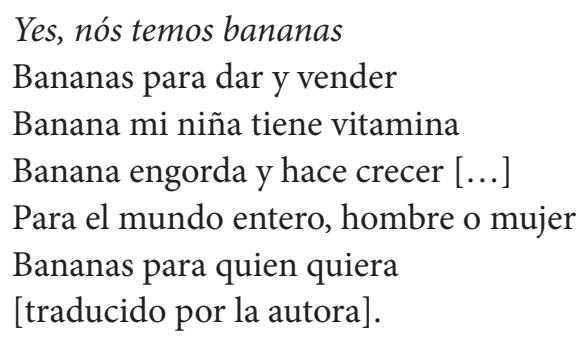

En su exuberante puesta en escena, Matogrosso introduce novedosas disidencias frente a la bananización recurrente de América Latina. El gesto homoerótico de su interpretación acentúa las vibraciones de su cuerpo travestido, mientras los efectos safónicos de su voz parecen deleitarse en una procesión del fruto, que a través de su degustación resulta irreductible al círculo monótono del universo colonizador. Esta diversidad contestataria se ilustra en la elección de la canción $O$ vendedor de bananas, compuesta en 1969 por Jorge Ben.

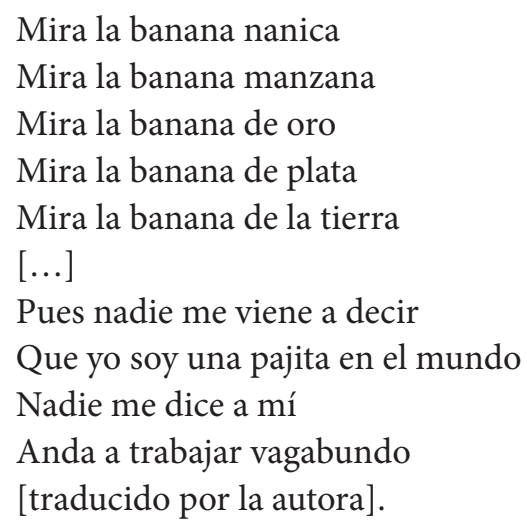

Así, los refinados mecanismos de control y vigilancia son impugnados a través de la intensidad de este derroche de sabores. Desde la erotización paródica del fruto no solo se introduce un quiebre del círculo monótono de las relaciones de poder, sino también un tránsito interpasional e improductivo frente a los estigmas que pesan sobre la sexualidad. Pero lo interesante es que esta embestida se introduce y se produce desde dentro, en el lugar exacto en que operan las iconografías normativas y heterodesignantes de una industria cultural entrampada en un orden militarizado. Iluminada por Matogrosso, la banana es descargada del logos colonialista y dictatorial, perdiendo su seriedad falogocéntrica, para (de)volverse finalmente y aún bajo el peso de la historia: lúdica, interpasional, deleitosa y, a pesar de todo, dolorosamente divertida. 


\section{Conclusión}

Parafraseando la bella sentencia de Foucault, podría decirse que los casos presentados permiten entrever "cómo aquello que hace fuerte al poder puede convertirse en aquello por lo que es atacado" (104). La performatividad postulada por Butler también apunta a estos intersticios del poder, donde el discurso - en sus efectos- es uno de sus principales vectores (Cuerpos 267). No obstante, es en la "falta" de su fijeza donde reside la oportunidad de acciones que pueden "volver el poder contra sí mismo para producir modalidades alternativas" (338). Desde esta sugerente línea de fuga, se abrieron algunas esferas hermenéuticas por donde explorar relaciones posibles entre sexo y género, subversión y poder, en las prácticas performativas de Ney Matogrosso y Carmen Miranda.

Teniendo en cuenta sus distancias epocales, es posible concluir que en ambos casos se visibilizan modalidades alternativas que inflexionan los discursos universalistas, en sus respectivas proyecciones (neo)coloniales y dictatoriales. Dentro de la "cadena ritual de resignificaciones" que implica la performance de género, Ney Matogrosso utiliza la parodia como estrategia estético-política de desestabilización de las identidades binarias y heteronormativas, que a su vez son parodiadas en las "actuaciones disonantes" de la propia diva. En clave poscolonial, es posible conjeturar que su coincidente despliegue de insubordinaciones podría ser parte de una reversibilidad inesperada y hasta ahora poco visibilizada.

En el caso de Matogrosso, el uso recurrente de la iconografía de la diva opera como práctica de subversión en niveles situados y corporeizados que confluyen en un devenir de apariciones. Movilidad que insistentemente encarna "luz, resplandor y adorno" (Castillo 92), frente a un modelo del terror de estado basado en la censura y la invisibilización sistemática de los cuerpos. Su reapropiación estilizada de "superficies de registro" - sayas, balangandãs, monedas, purpurina, religadas a la figuración de la banana- no funciona solo como un gesto de resistencia. Frente a los dispositivos de seguridad del estado, Matogrosso introduce formas inusitadas de desacato, que interrogan y a la vez desafían el imaginario revolucionario. Los tacones por el verde olivo, la nostalgia frente al olvido, el brillo contra el régimen de opacidad de los cuerpos, son parte de una propuesta creativa que instala lumínicas líneas de fuga que tensionan ambos lados de la trinchera patriarcal.

En este contexto, la diva es expropiada al discurso dominante y a la vez infiltrada en una red de superposiciones estéticas. Horadando los límites binarios entre lo masculino y lo femenino, lo político y lo espectacular, la reapropiación erotizada de sus bananas se despliega como embestida decolonial en el centro de sus significantes hegemónicos. En este sentido, es posible sostener que la interpretación de Ney Matogrosso ofrenda un brillo diferente a la diva, menos estridente tal vez, pero más liberador para el devenir en su cuerpo y otros cuerpos. ${ }^{13}$

13 La obra de Ney Matogrosso es extensa y poco conocida en los países que bordean el "continente" brasileño. En el año 2001 - ya consagrado en la escena del espectáculo - el artista dedicó un disco completo a Carmen Miranda, 
A contracorriente de las regulaciones del Estado y los filtros del mercado, las prácticas subversivas de Ney Matogrosso y Carmen Miranda parecen confirmar y a la vez rebasar la teoría butleriana. Tal vez porque — como señala Moraña - en nuestro contexto latinoamericano el principio barroco "se despliega y repliega en mensaje y silencio, celebración e impugnación, identidad y alteridad” (7). Desde la epistemología de la pose parece vislumbrarse un entramado irrefrenable de "máscaras sobre la máscara” (Castillo 92). Antifaces que carnavalizan y a la vez provocan desplazamientos y "metáforas performativas" que - siguiendo a Braidotti- posibilitan encuentros y fuentes de interacción, experiencia y conocimiento, "que de otro modo difícilmente habrían tenido lugar" (Sujetos nómades 32). La complicidad que ha podido entreverse en sus formas de desacato, se extiende como una invitación para explorar otros pliegues posibles, otras zonas de intensidad que barrocamente alteran y resisten, ajenas a los "pecados" que históricamente fueron endosados "al sur del ecuador" (Matogrosso).

\section{Referencias}

Adams, Frederick. Conquest of the tropics: The Story of the Creative Enterprises Conducted by the United Fruit Company. Nueva York, Garden City, 1914.

Amaral, Rita. "Foi conta para todo canto: As religiões afro-brasileiras nas letras do repertório musical popular brasileiro”. Afro-Ásia, no 34, 2006, pp. 189-235.

Bahiana, Ana Maria. “O 'Feitiço' de Ney Matogrosso”. O Globo, Rio de Janeiro, 21 ago. 1978a.

Bajtin, Mijail. La cultura popular en la Edad Media y en el Renacimiento. Madrid, Alianza, 2003.

Baker, Valeria. “The Banana as Icon: Orientalism, Violence, and the Problem of Memory in Fallas's 'Mamita Yunai', Reyes-Manzo's Photography and the Cultural Imagery”. Tesis para optar al grado de Magíster en Memoria Cultural, Universidad de Londres, 2009.

Balieiro, Fernando. "Carmen Miranda entre os desejos de duas nações: cultura de massas, performatividade e cumplicidade subversiva em sua Trajetória”. Tesis para optar al grado de Doctor en Sociología, Universidade Federal de São Carlos, 2014.

Banana da terra. Dirigida por Ruy Costa, Sonofilmes, 1939.

Barthes, Roland. La cámara lúcida: Nota sobre la fotografía. Barcelona, Paidós, 1990.

Bataille, Georges. El Erotismo. Barcelona, Tusquets, 1997.

Ben, Jorge. "Vendedor de bananas". Os Incríveis, RCA, 1969.

Batuque, cuyas giras promocionaron otras estilizadas reapropiaciones de la diva. Pero esto ya es parte de otros devenires bajo el "tornasol de Ipanema" (Lemebel 101). 
Benavente, Carolina. (2010). “Divina’: Consagración cultural y usos de lo sagrado en la actriz mexicana María Félix (1914-2002)”. Convergencia Revista de Ciencias Sociales, no 52, 2010, pp. 261-288.

Benjamin, Walter. Discursos interrumpidos I. Buenos Aires, Taurus, 1989.

Borges, José Paulo. “Ney babados e requebros”. Ultima Hora São Paulo, 1 jun. 1979.

Braidotti, Rosi. Sujetos nómades: Corporización y diferencia sexual en la teoría feminista contemporánea. Buenos Aires, Paidós, 2000.

- - Metamorfosis: Hacia una teoría materialista del devenir. Madrid, Akal, 2005.

Butler, Judith. "Actos performativos y constitución del género: un ensayo sobre fenomenología y teoría feminista”. Debate feminista, n¹8, 1998, pp. 296-314.

-_. Cuerpos que importan. Sobre los límites materiales y discursivos del "sexo". Buenos Aires, Paidós, 2002.

- - Lenguaje, poder e identidad. Madrid, Síntesis, 2004.

- - El género en disputa: El feminismo y la subversión de la identidad. Barcelona, Paidós, 2007.

Cangi, Adrián. "Margen del deseo. Lo que vemos, lo que nos mira”. El cuerpo queer, Subvertir la hétero-normatividad. Comp. Jean Allouch. Buenos Aires, Ediciones Letraviva, 2015, pp. 61-96.

Castillo, Alejandra. "La virgen barroca y las prácticas artísticas en América Latina”. Cuestiones de Filosofía, no 16, 2014, pp. 89-95.

Castro, Ruy. Carmen: uma biografia. São Paulo, Companhia das Letras, 2005.

Coelho, José Ligiéro. "Carmen Miranda: An Afro-Brazilian Paradox". Tesis para optar al grado de Doctor en Estudios de Performance, Universidad de Nueva York, 1998.

Da Silva, Robson. “'Sou quem sou, e não sou nada, sou uma história já contada’: Sujeitos cênicos -expressão erótica na obra audiovisual de Ney Matogrosso no contexto de autoritarismo (1975-1982)". Antíteses, no 16, 2015, pp. 303-326.

Debord, Guy. La sociedad del espectáculo. Santiago de Chile, Naufragio, 1995.

Deleuze, Gilles y Félix Guattari. Mil Mesetas. Capitalismo y esquizofrenia. Valencia, Pre-textos, 2002.

Dyer, Richard. Las estrellas cinematográficas: Historia, ideología, estética. Buenos Aires, Paidós, 2001.

Echavarren, Roberto. Arte andrógino: estilo versus moda en un siglo corto. Santiago de Chile, Ripio Ediciones, 2008.

-—. "Reseña de El cuerpo queer”. Nácate, 2016, pp. 1-9.

"Feitiço”. Ney Matogrosso - Baú de Raridades. 26 jun. 2008. Web. 20 jul. 2018.

Foucault, Michel. Microfísica del poder. Madrid, Ediciones de La Piqueta, 1979.

Galeano, Eduardo. Las venas abiertas de América latina. Montevideo, Latinoamericana, 2011.

Green, James y Renan Quinalha, editores. Ditadura e homossexualidades: repressão, resistência e a busca pela verdade. São Carlos, EdUFSCar, 2014. 
Guattari, Félix y Suely Rolnik. Micropolítica. Cartografías del deseo. Madrid, Traficantes de sueños, 2006.

Halperin, David. “Amor Loca”. Revista de Psicología Universidad de Antioquia, no 2, 2010, pp. 57-75.

Jelin, Elizabeth. "Subjetividad y esfera pública: El género y los sentidos de familia en las memorias de la represión”. Política y Sociedad, no 3, 2011, pp. 555-569.

Jenkins, Virginia. Bananas: An American History. Washington, Smithsonian Books, 2000.

Lemebel, Pedro. Loco afán: Crónicas de sidario. Santiago de Chile, LOM, 1997.

Matogrosso, Ney. Feitiço. WEA Discos, 1978.

Molloy, Sylvia. "La política de la pose”. Las culturas de fin de siglo en América Latina. Ed. Josefina Ludmer. Buenos Aires, Beatriz Viterbo, 1994, pp. 128-138.

- - Poses de fin de siglo: Desbordes del género en la modernidad. Buenos Aires, Eterna Cadencia, 2012.

Moraña, Mabel. Viaje al silencio: Exploraciones del discurso barroco. Alicante, Biblioteca Virtual Miguel de Cervantes, 2005.

Morin, Edgar. Las stars: Servidumbres y mitos. Barcelona, Dopesa, 1972.

Olavarría, José, editor. Hombres: identidad/es y violencia: $2^{\circ}$ Encuentro de Estudios de Masculinidades: identidades, cuerpos, violencia y políticas públicas. Santiago de Chile, FLAcso, 2001.

Owens, Craig. "Posar". Efecto Real: Debates posmodernos sobre fotografía. Ed. Jorge Ribalta. Barcelona, Gustavo Gili, 2004, pp. 194-215.

Pavis, Patrice. El análisis de los espectáculos. Barcelona, Paidós, 2000.

Preciado, Beatriz. Manifiesto contrasexual. Barcelona, Anagrama, 2011.

Queiroz, Flávio. "Ney Matogrosso: sentimento contramão. Transgressão e autonomia artística”. Tesis para optar al grado de Doctor en Sociología, Universidade Federal de Ceará, Brasil, 2009.

Ribeiro, Alberto. "Yes! Nós temos bananas". Almirante, Odeon, 1937.

Richard, Nelly. Residuos y metáforas: (ensayos de crítica cultural sobre el Chile de la transición). Santiago de Chile, Cuarto Propio, 1998.

Roberts, Shari. "The Lady in the Tutti-Frutti Hat: Carmen Miranda, a Spectacle of Ethnicity". Cinema Journal, no 3, 1993 pp. 3-23.

Rodrigues, Jorge. "Identidades e ambiguidade de gênero nas capas de discos da MPB". Todas as Musas, $\mathrm{n}^{\circ}$ 2, 2014, pp. 2-14.

Rosenberg, Tiina. Don't Be Quiet, Start a Riot! Essays on Feminism and Performance. Estocolmo, Stockholm University Press, 2016.

The Gang's All Here. Dirigida por Busby Berkeley, 20th Century Fox, 1943.

Said, Edward. Orientalismo. Barcelona, Debolsillo, 2003.

Shaw, Lisa. Carmen Miranda. Londres y Nueva York, Palgrave Macmillan, 2013.

Taylor, Diana, editora. Estudios avanzados de Performance. Ciudad de México, Fondo de Cultura Económica, 2011. 
- - El archivo y el repertorio: La memoria cultural performática en las Américas. Santiago de Chile, Ediciones Universidad Alberto Hurtado, 2017.

Zan, José Roberto. “Secos \& Molhados: o novo sentido da encenação da canção". VII Congreso Latinoamericano de la Asociación internacional para el estudio de la Música Popular (IASPM-AL). La Habana, 19-24 de junio de 2006. La Habana: Casa de las Américas, 2006. 282-295.

Enviado: 22 julio 2018 Aceptado: 6 marzo 2019 